\title{
Analysis of GC-FID and GC-MS Microwave-Assisted Hydrodistillation Extraction (MAHD) of Agarwood Chips
}

\author{
Norfatirah Muhamad Sarih ${ }^{1}$, Nurlaila Ismail ${ }^{2 *}$, Nadeem Akhtar ${ }^{1}$, Saiful Nizam \\ Tajuddin ${ }^{1}$
}

${ }^{1}$ Bio-Aromatic Research Centre of Excellence,

Universiti Malaysia Pahang (UMP), Pahang, MALAYSIA

${ }^{2}$ School of Electrical Engineering, College of Engineering,

Universiti Teknologi MARA, Shah Alam, Selangor, MALAYSIA

*Corresponding Author

DOI: https://doi.org/10.30880/ijie.2021.13.06.017

Received 13 August 2019; Accepted 30 May 2021; Available online 31 August 2021

\begin{abstract}
This paper presents an analysis of Gas Chromatography - Flame Ionization Detector (GC-FID) and Gas Chromatography - Mass Spectrometry (GC-MS) microwave-assisted hydrodistillation extraction (MAHD) of agarwood chips. The work involves of agarwood chips sample preparation starting from drying to soaking process, extraction method using MAHD and compound analysis using GC-FID and GC-MS for compounds identification. During the extraction time, four hours were varied; 2-hours, 3-hours, 4-hours The result showed that the agarwood chips in this study, extracted by MAHD are made up of three major groups; oxygenated sesquiterpenes, monoterpene hydrocarbons, and sesquiterpene hydrocarbons. Not limited to that, the study also adds to the understanding of the variation of the chemical compounds in agarwood especially those contributed to the fragrance of its oil as well as together with different hours of extraction time where n-hexadecanoic acid appeared as the compound to have the high peak of relative peak area $(\%)$ at all $(5,4,3$ and 2$)$ time of extractions.
\end{abstract}

Keywords: Agarwood Chips, GC-FID, GC-MS, Microwave-assisted hydrodistillation extraction (MAHD), extraction time

\section{Introduction}

Agarwood oil is the oil extracted from agarwood trees. Agarwood or gaharu is the resin impregnated heartwood of the Aquilaria species, a genus which belongs taxonomically to the Thymelaeaceae family. The agarwood oil is highly demanded due to its special usage such as incense for religious ceremony, in perfume and traditional medicine preparations [1]. In the Middle East, it is a symbol of wealth and widely used during the wedding ceremony [2-3].

Extraction process for agarwood oil is the most important and initial step for analysis the botanical and plant matrices. The point of extraction is to make target compounds suitable for isolation from the matrices or/and analysis. Several distinctive extraction methods have been identified such as conventional method (hydrodistillation, solvent extraction, Soxhlet extraction) and alternative extraction techniques such as Microwave-Assisted Extraction (MAE), Supercritical Fluid Extraction (SFE), Ultrasound-Assisted Extraction (UAE) and Accelerated Solvent Extraction (ASE) [4]. However, the conventional extraction methods mainly are time consuming, laborious, additionally, they involve lengthy operation procedures, large solvent consumption and ultimately thermal degradation of the target compounds at high temperature. Current tendencies aim at overcoming these problems either by the development of new extraction methods, or the improvement of old extraction method. There are several common methods to extract essential oil applied in research laboratories and industries. Each of the method has advantages and disadvantages affecting the extraction of high quality 
oil, such as, yield, duration of time, costing and ability to extract targeted compounds [5-7]. Therefore, in this paper the MAE as alternative extraction combined with hydrodistillation method was proposed. So the method is called Microwave-assisted hydrodistillation (MAHD).

The microwave extraction method is better method compared to other tradisional method, due to the great energy and time saving, and suitable for extractions of large sample in minimum time [8,9] reported that microwave -assisted hydrodistillation (MAHD) is the best method compared to the other conventional method of extraction as it uses microwave radiation to heat solvents quickly and efficiently thus selectively extract the target compounds. The literature survey covers some of the latest reported methods of microwave extraction. Microwave extraction methods are hence gaining greater acceptability in sensitive processes especially essential oil extraction. In recent years, this method has shown an increased affinity in the published study of method extraction.

\subsection{Gas Chromatography-Flame Ionization Detector (GC-FID)}

GC-FID is a technique to identify compounds based on retention time that convert into system-independent constants commonly known as Retention index (or Kovats index). The retention indices of each chemicals compound are calculated based on its retention time standardized to the retention times of nearby eluting n-alkanes (e.g. hexane, heptanes, octane). In point of fact, retention times differ with the individual chromatographic system as it depends on the type and length of the column, film thickness, diameter, velocity and pressure of the carrier gas and time consumed in the analysis. The derived retention indices are relatively independent of these parameters and allow comparing values measured by different analytical laboratories under varying conditions. Joulian and Konig, [10] believed that, retention indices could help in identification of components by comparing experimentally established retention indices with identified values. In spite of the extensive studies and use of linear retention indices, it needs to be aware when using such indices in an absolute sense. Usually, data from one laboratory to another will commonly be not accurately reproduced, though by combining with mass spectral results, retention data does still provide a good guide to discover the identities of components.

\subsection{GC-MS}

Gas chromatography-mass spectroscopy (GC-MS) is a combination of GC (highly efficient separation column) with specific or selective detectors (MS); thus makes GC a more favourable technique [11]. The GC-MS also known as hyphenated analysis technique whereas; the combination of spectroscopic detection methods or other detection techniques in order to get better separation of the components or quality of data from an analysis [12]. Gas chromatography, as mentioned, is to separate the elements of a mixture while mass spectroscopy characterizes each of the elements individually thus, a solution that containing a number of chemicals can be qualitatively and quantitatively evaluated [13] claimed that this method can be used to analyze mixtures of chemicals including essential oils. The MS is a technique of analysis that engages generating charged particles (ions) from molecules of the analytes. The generated ions are actually analyzed to supply information about the molecular weight of the compound and its chemical structure. There are three main separate regions in mass spectrometers include; ion source (ionizer), mass (ion) analyzer, and detector [14]. The schematic diagram of GC-MS is shown in Fig. 1 [14].

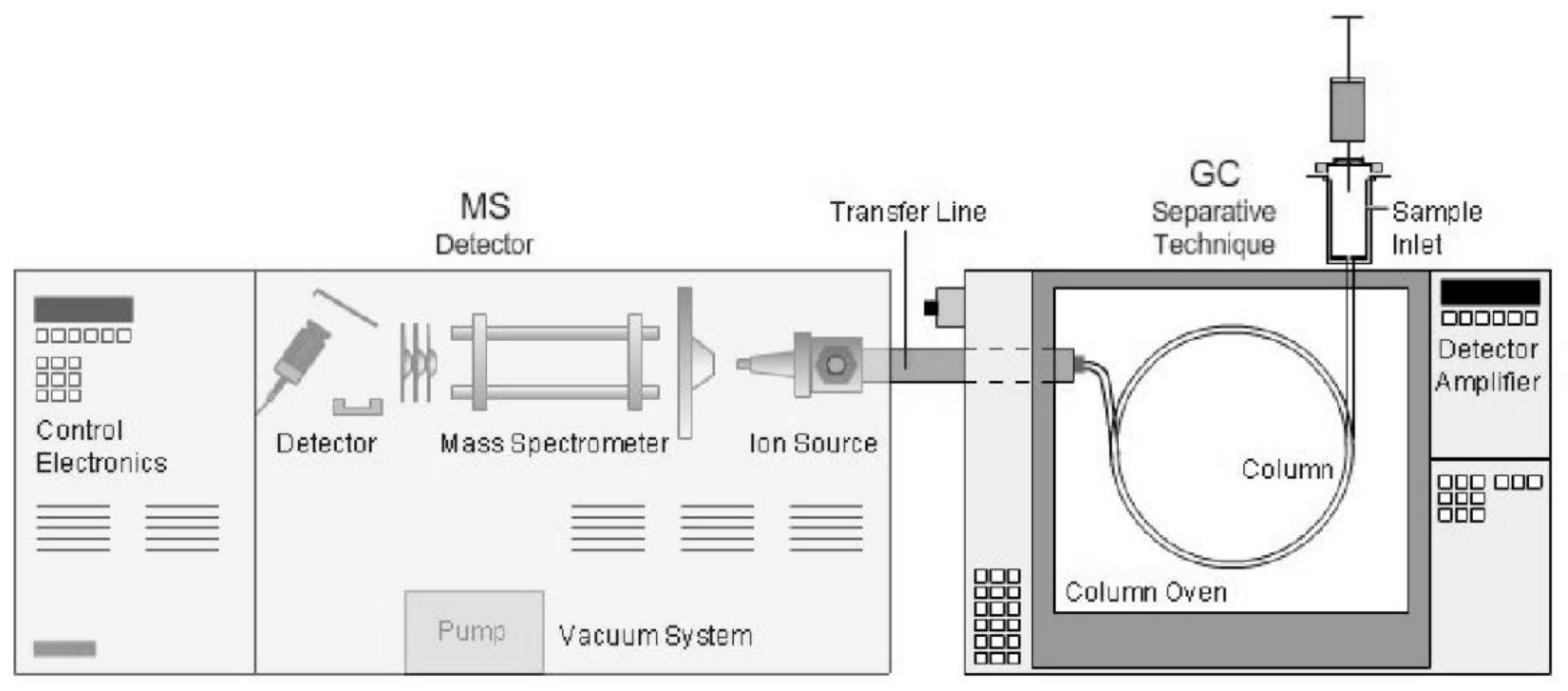

Fig. 1 - Schematic Diagram of GC-MS [14] 
In many cases, mass spectra are not mainly distinctive for MS of essential oils. In analysis of essential oils, the main problem is identification of the constituents that have isomers with similar mass. For instance, the mass spectra of terpenes compound maybe closely similar, due to consist of a large number of isomers of the same molecular formula but with different structure exist. Consequently, it makes automated identification based on this data become difficult. A nonspectroscopic detector for example, FID can only supply a net response for each analytes elute from the column. Complex compounds especially in essential oils may have multiple overlapping peaks, and then there will always be uncertainty as to the purity of any recorded peak. If one cannot be declared as to the purity of a peak, then quantitative analysis of a component based on FID data only may be inaccurate. The MS may able to identify overlapping peaks and assign relative amounts of components where overlaps occur. Either retention time or mass spectral information alone is inadequate to provide positive identification of many essential oils. Therefore; a greater approach is to combine the GC-FID data (retention indices) with GC-MS data (mass spectra) can enhance the quality of data in order to identify compounds. Marriott et al., 2001 claimed that these two independent parameters will be able to support the identification of compound. Adams [15] and Jennings and Shibamoto [16] have developed a list of the retention index of compounds and their mass spectra in order of elution in their studies. The identification of unknown compounds has been entrenched by using retention indices in conjunction with GC-MS data [17]. Refer to Fig.2 for GC-FID schematic diagram.

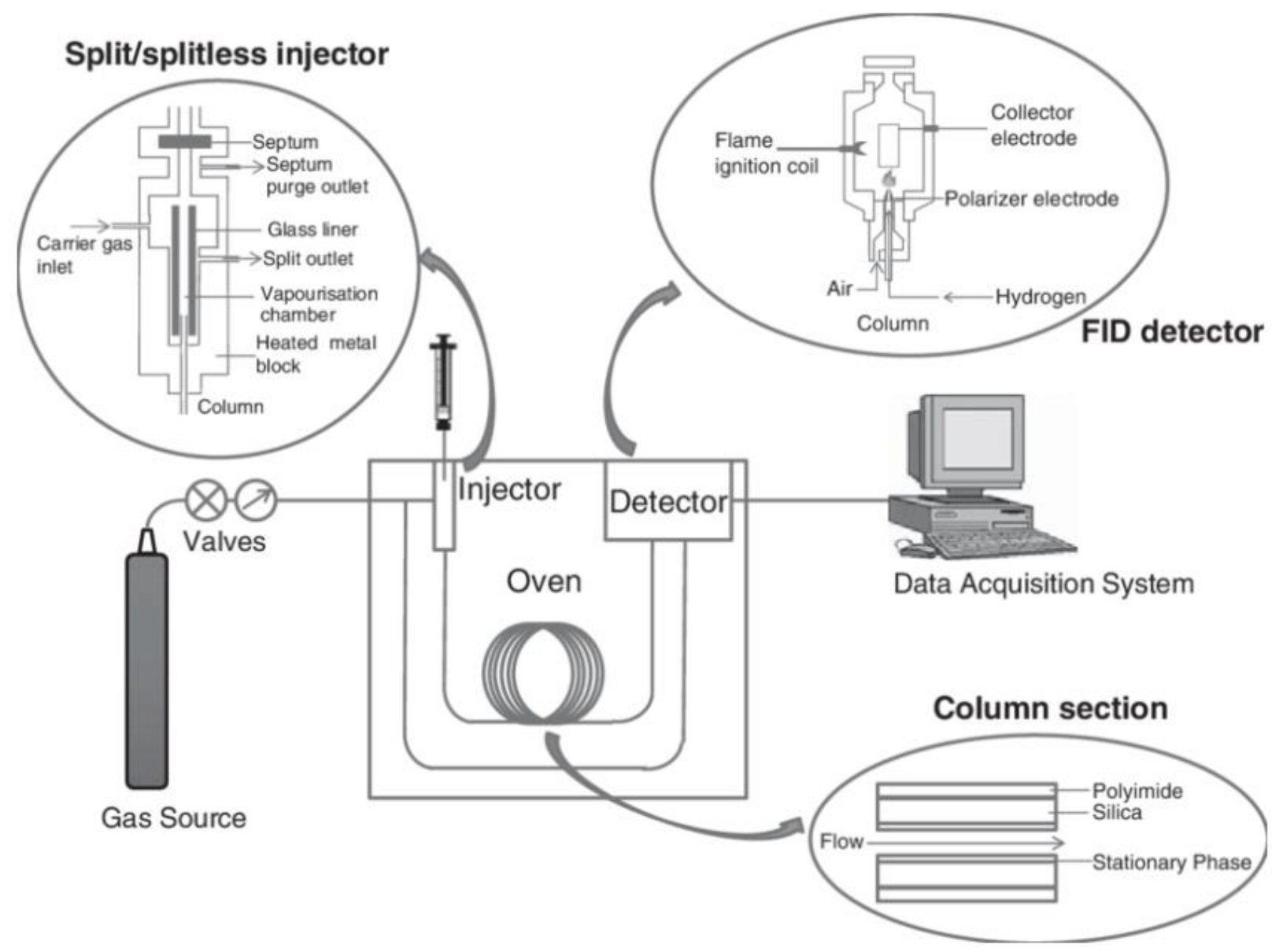

Fig. 2 - GC-FID Schematic Diagram [17]

\subsection{Microwave-Assisted Extraction and Hydrodistillation (MAHD)}

Microwave extraction is a recent process designed for the extraction of essential oil. The extraction method can be pertained to two phases of extraction which are the first phase is liquid extraction; liquid as solvent and the second phase is called gas extraction; gas acts as extractant. Usually for the first phase (liquid phase extraction), this is the stage for essential oils from plants to be isolated. The microwave irradiation has been a subject in order to absorb microwave energy in different ability which will be depending to chemical nature of the species. The whole irradiation fulfilled its basic principle. The dielectric constant is generally used to measure the physical property of the process. Thus, liquid phase extraction assisted by microwave is based on the fact that it is possible to immerse the matrix to be extracted into a solvent that is characterized both by a low dielectric constant and a relative transparency to microwaves. The sample that needs to be extracted is placed in the microwave reactor, with or without any added solvent or water. Then cells of 
the sample will swell up by the internal heating of water within the sample and the glands and oleiferous receptacles burst. Thus, this process frees the essential oil, which is evaporated with the in-situ water in the plant material. A cooling system outside the microwave oven continuously condenses the vapor which is collected. The excess water is refluxed back into the extraction vessel so as to restore the in-situ water to the sample [8]. The schematic diagram of MAHD is displayed in Fig. 1 [8].

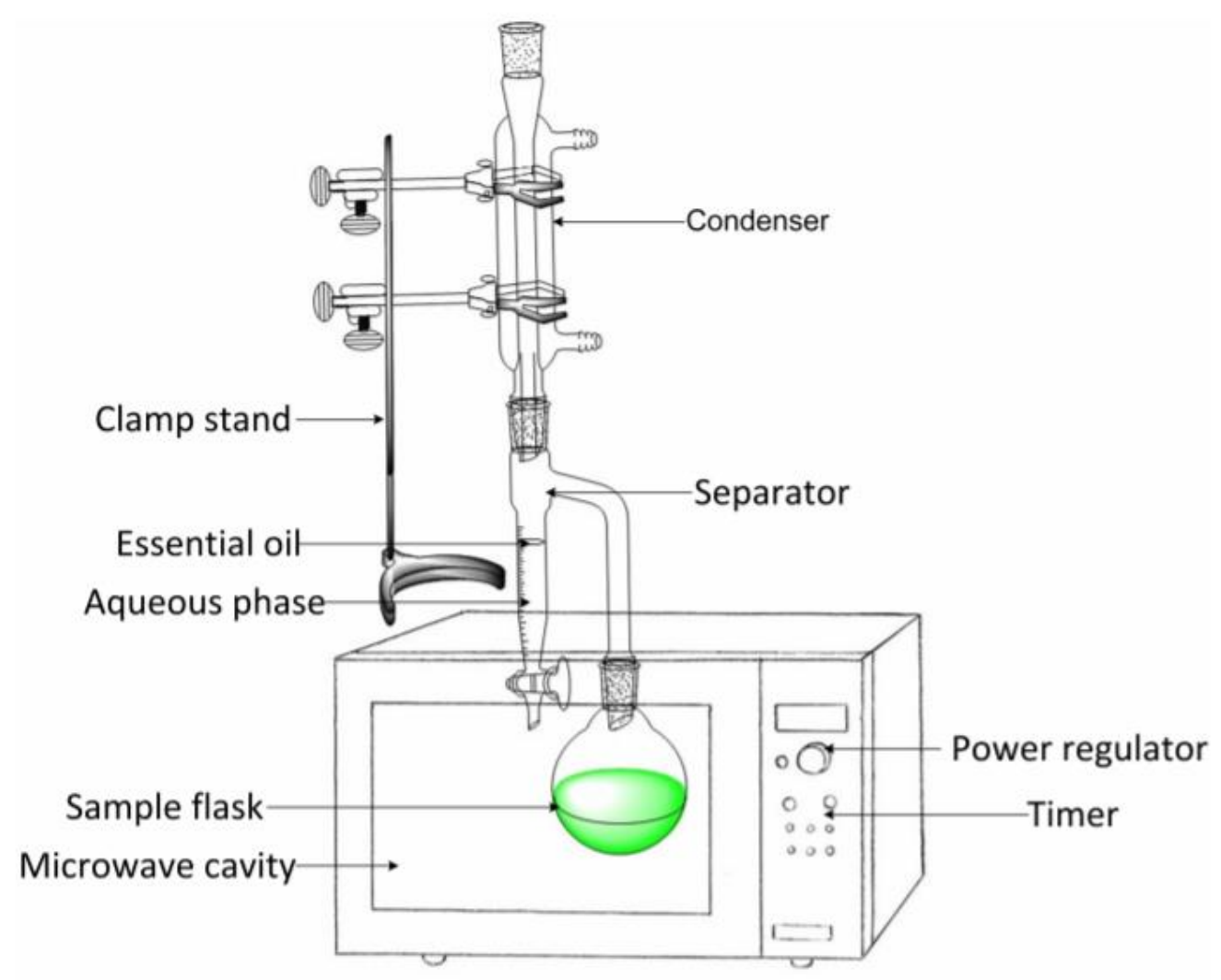

Fig. 3 - Schematic Diagram of MAHD [18]

\section{Material and Method}

\subsection{Sample preparation}

Aquilaria malaccensis sample was obtained from Gua Musang, Kelantan Forest (Malaysia), procured from Mazlan Mohamed, an agarwood trader certified by the Forestry Department, Malaysia. At the first stage, the drying process is done in which the agarwood chips were cut into smaller pieces to increase surface area of chip wood to facilitate the drying process. The chips were dried in a plant drying oven at $40{ }^{\circ} \mathrm{C}$ until the weight is constant. After that is grinding process. Here, the pieces of dry agarwood chips were ground into milled agarwood to increase the rate of extraction as the higher the surface area of milled agarwood in contact with extracting medium, more essential oil can be extracted. Agarwood that was larger than $1 \mathrm{~mm}$ after grinding will be ground again. Large portions of trunk were chopped into 10 $\mathrm{cm}$ chips prior to grinding. The milled agarwood was dried again in an oven at $40{ }^{\circ} \mathrm{C}$ for about two to three hours and sealed in a plastic bag prior to extraction. Next is the soaking step. In this stage, mass of ground agarwood sample used in this experiment was $100 \mathrm{~g}$. The ground agarwood was soaked in distilled water (ratio of agarwood to water was 1:10) for 7 days [18 - 20]. Then, the soaked agarwood went through the extraction process.

\subsection{Extraction Method - Microwave-Assisted Hydrodistillation (MAHD)}

Microwave-assisted hydrodistillation (MAHD) was performed in a Milestone "Microwave Clevenger" microwave laboratory oven, a multimode microwave reactor $230 \mathrm{~V} / 50 \mathrm{~Hz}$ with a maximum delivered power of $800 \mathrm{~W}$. The dimensions of the PTFE-coated cavity of the microwave were $35 \mathrm{~cm} \times 35 \mathrm{~cm} \times 35 \mathrm{~cm}$. "Easy-WAVE" software was controlled time, temperature, pressure and power during the extraction. Temperature was monitored by a shielded thermocouple (ATC-300) inserted directly into the sample container and by an external infrared (IR) sensor. Temperature was controlled by a feedback to the microwave power regulator. The experimental MAHD variables have been optimized by the unvaried method in order to maximize the yield of essential oil. $100 \mathrm{~g}$ of agarwood samples were soaked in a $2 \mathrm{~L}$ round bottom flask containing distilled water $(1000 \mathrm{~mL})$. The flask was setup within the microwave oven cavity and a 
condenser was used on the top (outside the oven) to collect the extracted essential oils. The microwave extraction was operated at $500 \mathrm{~W}$ power levels for period of 2, 3, 4 and $5 \mathrm{~h}$. The extracted essential oils were then dried over anhydrous sodium sulfate, weighed and stored in amber vials at $4{ }^{\circ} \mathrm{C}$ until they were used for analysis. All the results are reported in $\mathrm{g}$ of essential oils per $100 \mathrm{~g}$ of dried agarwood.

\subsection{Analysis Method - GC-FID and GC-MS}

GC-FID: The components of essential oil of agarwood obtained by different extraction method were analyzed by GC-FID (Agilent 7890A gas chromatograph) as shown in Figure 3.5, using a DB-1MS capillary column (0.25 mm I.D.; $0.25 \mu \mathrm{m}$ film thickness). The instrument was equipped with a flame ionization detector (FID). The operation condition was as follows: Helium carrier gas flow rate was $1.0 \mathrm{~mL} / \mathrm{min}$; split ratio of 1:5 with injection volume $1 \mu \mathrm{L}$; temperatures of injector and detector were set at $250{ }^{\circ} \mathrm{C}$ respectively; oven temperature was programmed at $60{ }^{\circ} \mathrm{C}$ for 3 min, then ramped at $3{ }^{\circ} \mathrm{C} / \mathrm{min}$ to $240{ }^{\circ} \mathrm{C}$ and held for $10 \mathrm{~min}$. The components were identified on the basis of comparison of their retention indices. Retention indices were calculated using a homologous series of $n$-alkanes $\left(\mathrm{C}_{7}-\mathrm{C}_{24}\right)$.

GC-MS: The composition analysis of agarwood oils was performed by using gas chromatography (GC) apparatus coupled with a mass spectrometry (MS), GC-MS, model Agilent 7890A Network System gas chromatography (Figure 3.6). It was attached to a mass spectrometer (Agilent 5975C) with detector in full scan mode under electron impact ionization (EI, $70 \mathrm{eV})$ and equipped with a DB-1MS capillary column $(30 \mathrm{~m} \times 0.25 \mathrm{~mm}$ I.D.; $0.25 \mu \mathrm{m}$ film thickness). The oven temperature was programmed for $60{ }^{\circ} \mathrm{C}$ for $3 \mathrm{~min}$, then ramped at $3{ }^{\circ} \mathrm{C} / \mathrm{min}$ to $240{ }^{\circ} \mathrm{C}$ and held for $10 \mathrm{~min}$. Injector inlet and detector temperatures were set at $250{ }^{\circ} \mathrm{C}$. Hexane was used as solvent to dilute each sample and then injected in $1 \mu \mathrm{L}$ volume in the split mode (ratio 1:5) using helium as carrier gas $(1 \mathrm{~mL} / \mathrm{min})$.

\section{Result and Discussion}

Table 1 tabulates the relative peak area (\%) of agarwood chips chemical compounds at 2, 3, 4 and 5 hours of extraction time. In general, all the chemical compounds identified were belong to three groups of terpenes with respect to 4 different hours. They are monoterpenes hydrocarbons, sesquiterpenes hydrocarbons and oxygenated sesquiterpenes. The overall relative peak area for the first group which is monoterpene hydrocarbons is as follows; at 2-hours is $6.6 \%$, 3-hours is $1.0 \%$, 4-hours is $7.8 \%$ and 5-hours is $12.1 \%$. Next, for the second group which is sesquiterpenes hydrocarbons, the overall relative peak area is; 2 -hours is $1.6 \%, 3$-hours is $0.9 \%$, 4-hours is $2.18 \%$ and 5 -hours is 2.6 $\%$. Then, for the third group which is oxygenated sesquiterpenes the overall relative peak area is; 2 -hours is $65.8 \%, 3-$ hours is $59.6 \%$, 4-hours is $60.7 \%$ and 5-hours is $58.8 \%$. It can be seen that the most compounds exist in agarwood chips extracted by MAHD in this study is from the third group which is oxygenated sesquiterpenes. After that, another observation can be found that, the arrangements of the main compounds are quite different to different time of extraction. Among 4 hours of extraction time, the yield of compounds is different to each other. For monoterpenes hydrocarbons and sesquiterpenes hydrocarbons, 5-hours yield the highest amount at $12.1 \%$ and $2.6 \%$, respectively. However, for the oxygenated sesquiterpenes this group of compounds mostly appeared during 4-hours of extraction time with the yield amount of $60.7 \%$. The finding shows the versatility of the MAHD process for selectively separating a target component with regards to different time of extraction. In the other hand is, if individual compound was observed, at 5-hours of MAHD extractor for agarwood chips, the compounds with the highest boiling point (oxygenated sesquiterpenes) are largely predominant. 
Table 1 - The relative peak area (\%) of agarwood chips chemical compounds at 2, 3, 4 and 5 hours of extraction time

\begin{tabular}{|c|c|c|c|c|c|}
\hline \multirow{2}{*}{ Compounds } & \multirow{2}{*}{$\begin{array}{c}\text { Database } 1 \\
\text { (DB-1) }\end{array}$} & \multicolumn{4}{|c|}{ Time (hours) } \\
\hline & & 2 & 3 & 4 & 5 \\
\hline \multicolumn{6}{|l|}{ Monoterpene hydrocarbons } \\
\hline benzaldehyde & 934 & 0.0 & 0.0 & 0.0 & 0.3 \\
\hline 2-ethylhexanol & 1011 & 0.0 & 0.0 & 0.0 & 0.2 \\
\hline 4-phenyl-2-butanone & 1201 & 5.9 & 0.9 & 7.6 & 11.5 \\
\hline decanoic acid & 1354 & 0.7 & 0.1 & 0.2 & 0.2 \\
\hline \multicolumn{6}{|l|}{ Sesquiterpene hydrocarbons } \\
\hline$\beta$-Maaliene & 1414 & 0.0 & 0.0 & 0.2 & 0.2 \\
\hline$\alpha$-guaiene & 1440 & 0.0 & 0.0 & 0.1 & 0.2 \\
\hline aromadendrene & 1443 & 0.0 & 0.0 & 0.0 & 0.1 \\
\hline$\Upsilon$-gurjunene & 1472 & 0.0 & 0.0 & 0.0 & 0.1 \\
\hline$\beta$-agarofuran & 1474 & 0.0 & 0.0 & 0.2 & 0.1 \\
\hline$\alpha$-selinene & 1486 & 0.4 & 0.1 & 0.3 & 0.3 \\
\hline$\alpha$-muurolene & 1496 & 0.0 & 0.0 & 0.0 & 0.0 \\
\hline$\alpha$-bulnesene & 1503 & 1.2 & 0.8 & 1.4 & 1.6 \\
\hline \multicolumn{6}{|l|}{ Oxygenated sesquiterpenes } \\
\hline$\alpha$-elemol & 1530 & 1.2 & 0.3 & 0.7 & 0.9 \\
\hline$\alpha$-agarofuran & 1553 & 0.4 & 0.3 & 0.6 & 0.6 \\
\hline norketoagarofuran & 1557 & 1.0 & 0.2 & 0.1 & 0.2 \\
\hline epoxybulnesene & 1572 & 0.0 & 2.4 & 3.6 & 3.4 \\
\hline tetradecanal & 1593 & 1.0 & 0.8 & 1.3 & 1.3 \\
\hline caryophellene oxide & 1600 & 5.9 & 1.4 & 4.5 & 4.3 \\
\hline guaiol & 1603 & 1.7 & 3.5 & 6.0 & 5.9 \\
\hline 10-epi- $\gamma$-eudesmol & 1619 & 0.9 & 6.0 & 2.9 & 2.8 \\
\hline agarospirol & 1631 & 7.3 & 10.5 & 10.2 & 10.3 \\
\hline epi- $\alpha$-cadinol & 1640 & 1.0 & 0.7 & 1.0 & 1.1 \\
\hline jinkoh-eremol & 1643 & 5.8 & 0.7 & 0.5 & 0.5 \\
\hline tridecanoic acid & 1647 & 0.0 & 0.0 & 0.6 & 0.8 \\
\hline kusunol & 1650 & 0.0 & 1.1 & 0.4 & 0.7 \\
\hline$\alpha$-eudesmol & 1652 & 1.2 & 1.9 & 1.3 & 0.5 \\
\hline bulnesol & 1664 & 1.0 & 0.8 & 1.0 & 0.9 \\
\hline dehydrojinkoh-eremol & 1673 & 1.7 & 5.5 & 4.2 & 2.6 \\
\hline epi- $\alpha$-bisabolol & 1678 & 0.0 & 0.0 & 0.0 & 0.6 \\
\hline$\alpha$-bisabolol & 1683 & 0.0 & 0.0 & 0.0 & 0.4 \\
\hline selina-3,11-dien-9-one & 1689 & 0.0 & 0.4 & 1.0 & 0.8 \\
\hline pentadecanal & 1695 & 9.8 & 1.7 & 1.7 & 1.7 \\
\hline rotundone & 1703 & 0.0 & 0.7 & 0.5 & 1.7 \\
\hline selina-3,11-dien-9-ol & 1721 & 1.3 & 0.7 & 0.9 & 1.2 \\
\hline selina-4,11-dien-14-oic acid & 1728 & 0.0 & 1.1 & 1.2 & 0.7 \\
\hline selina-3,11-dien-14-al & 1735 & 0.0 & 2.3 & 2.9 & 4.7 \\
\hline
\end{tabular}




\begin{tabular}{llllll}
\hline 9,11-eremophiladien-8-one & 1740 & 1.7 & 0.0 & 0.8 & 0.2 \\
\hline selina-3,11-dien-14-ol & 1750 & 1.6 & 1.2 & 1.2 & 1.2 \\
\hline guaia-1(10),11-dien-9-one & 1752 & 1.0 & 1.0 & 0.8 & 0.5 \\
\hline selina-4,11-dien-14-al & 1758 & 1.4 & 0.0 & 0.4 & 0.4 \\
\hline guaia-1(10),11-dien-15-ol & 1770 & 1.0 & 0.8 & 0.5 & 0.4 \\
\hline selina-3,11-dien-14-oic acid & 1775 & 0.7 & 0.6 & 0.5 & 0.4 \\
\hline sinenofuranol & 1776 & 1.7 & 0.3 & 0.4 & 0.4 \\
\hline 2-hexadecanone & 1782 & 0.4 & 0.2 & 0.5 & 0.4 \\
\hline dihydrokaranone & 1799 & 1.7 & 0.2 & 0.5 & 0.9 \\
\hline karanone & 1812 & 0.0 & 0.9 & 0.5 & 0.7 \\
\hline oxo-agarospirol & 1822 & 0.4 & 0.5 & 1.9 & 0.7 \\
\hline pentadecanoic acid & 1842 & 0.0 & 0.3 & 0.6 & 0.6 \\
\hline n-hexadecanoic acid & 1950 & 13.0 & 10.2 & 4.6 & 3.0 \\
\hline Others & & & & & \\
\hline 1,5-diphenyl-2-pentene & 2000 & 0.0 & 0.2 & 0.3 & 0.3 \\
\hline oleic acid & 2020 & 0.0 & 0.2 & 0.1 & 0.1 \\
\hline
\end{tabular}

Fig. 4 shows the GC chromatograms of $500 \mathrm{~W}$ at 5-hours which dominantly to 10 major compounds as follows: (a) 4-phenyl-2-butanone, (b) decanoic acid, (c) $\beta$-agarofuran, (d) $\alpha$-bulnesene, (e) epoxybulnesene, (f) caryophellene oxide, (g) guaiol, (h) 10-epi- $\gamma$-eudesmol (i) agarospirol (j) n-hexadecanoic acid. From graphical observation, n-hexadecanoic acid peaks is the highest contributed to the highest amount of relative peak area (\%). After that it is followed by agarospirol. The different peaks of compounds resulted to the unique GC chromatogram trend for agarwood.

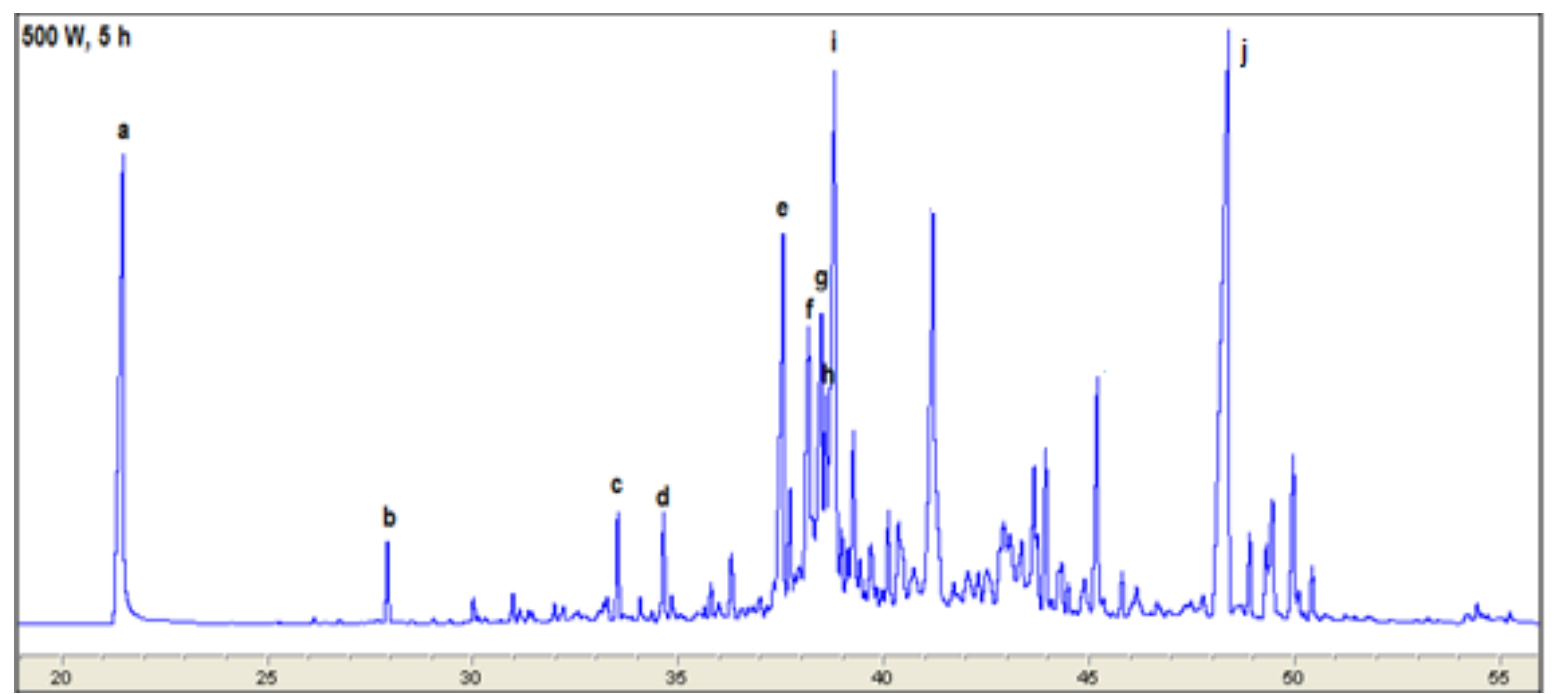

Fig. 4 - GC chromatograms of $500 \mathrm{~W}(5 \mathrm{~h})$ (a) 4-phenyl-2-butanone; (b) decanoic acid; (c) $\beta$-agarofuran; (d) $\alpha$ bulnesene; (e) epoxybulnesene; (f) caryophellene oxide; (g) guaiol; (h) 10-epi- $\gamma$-eudesmol; (i) agarospirol; (j) nhexadecanoic acid 
Chemical compounds at 2, 3, 4 and 5 hours of extraction time

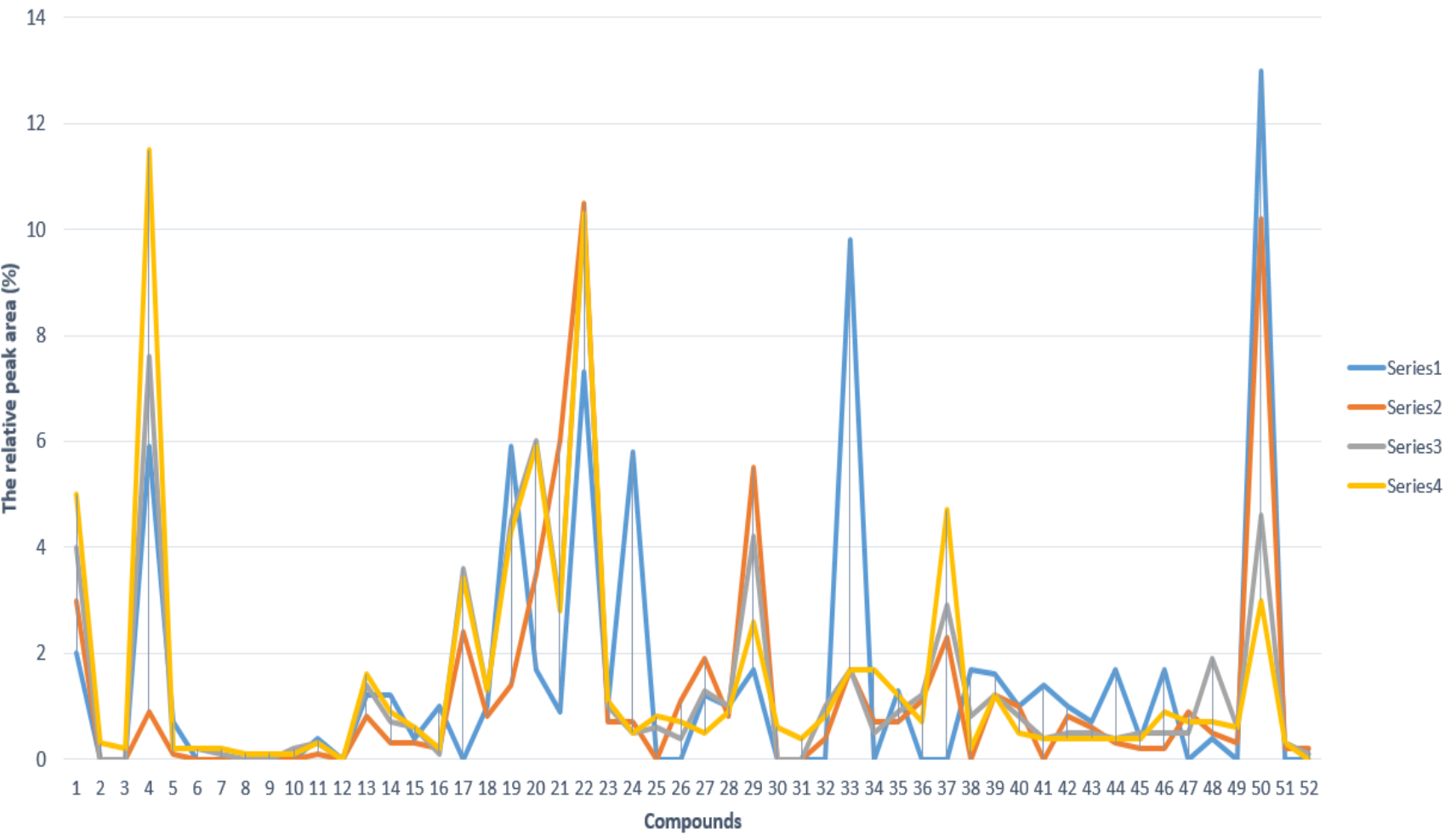

Fig. 5 - Chemical compounds at 2, 3, 4 and 5 hours of extraction time

This study has found that generally the compositions of agarwood oil obtained were oxygenated sesquiterpenes, monoterpene hydrocarbons, and sesquiterpene hydrocarbons. The composition of these terpenes shows their contribution to the fragrance of the agarwood essential oil. Not limited to that, the oxygenated compounds are more valuable as they are highly odoriferous.

Fig. 5 shows the chemical compounds at 2, 3, 4 and 5 hours of extraction time. There are 52 compounds produced at 2, 3, 4 and 5 hours of extraction. Series 1 is for 2 hours, Series 2 is for 3 hours, Series 3 is for 4 hours and Series 4 is for 5 hours of extraction. In general, it can be seen that, different extraction time, yielded different number of compounds as well as different the relative peak area $(\%)$ for every compounds. It was found that, at 5 hours of extraction, 4 significant peaks were observed that belongs to Compound no. 4 (4-phenyl-2-butanone), Compound no. 22 (agarospirol), Compound no. 37 (selina-3,11-dien-14-al) and Compound no. 50 (n-hexadecanoic acid). Then, at 4 hours of extraction, there are 4 peaks but all of them are lower than the peaks at 5 hours of extraction. They are Compound no. 4 (4-phenyl-2-butanone), Compound no. 29 (dehydrojinkoh-eremol), Compound no. 37 (selina-3,11-dien-14-al) and Compound no. 50 (nhexadecanoic acid). After that, at 3 hours of extraction, 3 high peaks are observed that belongs to Compound. No 22 (agarospiral), Compound no. 29 (dehydrojinkoh-eremol) and Compound no. 50 (n-hexadecanoic acid). Next is at 2hours of extraction, 6 high peaks are appeared that belongs to Compounds no. 4 (4-phenyl-2-butanone), Compound no. 19 (caryophellene oxide), Compound no. 22 (agarospirol), Compound no. 24 (jinkoh-eremol), Compound no. 33 (pentadecanal) and Compound no. 50 (n-hexadecanoic acid). Overall, it was revealed that Compound no. 50 (nhexadecanoic acid) has the high peak of relative peak area (\%) at all (5, 4, 3 and 2) hours of extraction time. It means that this compound is very significant for agarwood chips sample especially using GC-FID and GC-MS Microwave-Assisted Hydrodistillation Extraction (MAHD). 


\section{Conclusion}

The study in this paper has successfully analyzed the GC-FID and GC-MS microwave-assisted hydrodistillation Extraction (MAHD) of agarwood chips. It is the one of empirical investigation into the impact of agarwood chips compounds identification especially by varying the extraction time of 2-hours, 3-hours, 4-hours and 5-hours. This study also discovered that three major groups were exist; oxygenated sesquiterpenes, monoterpene hydrocarbons, and sesquiterpene hydrocarbons. Not limited to that, the study also revealed that at different hours of extraction time, different compounds with their unique relative peak area $(\%)$. Then, for the agarwood chips sample, n-hexadecanoic acid appeared as the compound to have the high peak of relative peak area (\%) at all (5, 4, 3 and 2) time of extractions. In spite of its limitations, the study certainly adds to the understanding of the variation of the chemical compounds in agarwood especially those contributed to the fragrance of its oil.

\section{Acknowledgement}

The authors would like to acknowledge MOHE for the FRGS grant coded: 600-IRMI/FRGS 5/3 (031/2019) awarded to Nurlaila Ismail, School of Electrical Engineeering, College Of Engineering, UiTM, Bioaromatic Research Centre of Excellence (BARCE), UMP and all staff involved.

\section{References}

[1] Akter, N. and Neelim, N. 2008. Agarwood plantation at BRAC Tea Estate: Introduction, environmental factors and financial analysis. BRAC Research Report. Bangladesh.

[2] Abdul Rashid, A.M., and Ahmad Zuhaidi, Y. 2011. Tapping the Wealth from Karas (Aquilaria malaccensis) tree.Malayan Forest Record. Selangor: Reka Cetak Sdn. Bhd.

[3] Adam, F., Tajuddin, S.N., Yusoff, M.M. and Johari, J. 2012. Rahsia dan Keunikan Gaharu. Pahang: UMP Books.

[4] Kaufmann, B. and Christen, P. 2002. Recent extraction techniques for natural products: microwave-assisted extraction and pressurised solvent extraction.Phytochemistry Analitycal. 13(2): 105-113.

[5] Augusto, F., Lopes, A. L. and Zini, C. A. 2003. Sampling and sample preparation for analysis of aroma and fragrances. Trends in Analytical Chemistry. 22(3):160-169.

[6] Boris, L. M. 2005. Identification of chemical compounds. Trends in Analytical Chemistry. 24: 493-508.

[7] Luque De Castro, M.D, Jiménez-Carmona, M.M. and Fernández-Pérez, V. 1999. Towards more rational techniques for the isolation of valuable essential oils from plants. Trends in Analytical Chemistry. 18 (11): 708-716.

[8] Ferhat, M.A., Meklati, B.Y. and Chemat, F. 2007. Comparison of different isolation methods of essential oil from Citrus fruits: Cold pressing, hydrodistillation and microwave "dry" Distillation. Flavour and Fragrance Journal. 22: 494-504.

[9] Lucchesi, M.E., Chemat, F. and Smadja, J. 2004. Solvent free microwave extraction of essential oil from aromatic herbs: Comparison with conventional hydrodistillation. Journal of chromatography A: 1043: 323-327.

[10] Joulain, D. and Konig, W. A. 1998. The atlas of spectral data of sesquiterpene Hydrocarbons. E.B.-Verlag. Germany.

[11] Idrayanto, G., and Yuwono, M. 2010. Encyclopedia of Chromatography. Cazes, J. Third edition. 3. United Kingdom and New York, US. CRC Press Taylor and Francis Group. 987.

[12] Marriott, P.J., Shellie, R. and Cornwell, C. 2001. Gas chromatographic technologies for the analysis of essential oils. Journal of Chromatography A. 936(1-2):1-22.

[13] Deng, C., Liu, N., Gao, M. and Zhang, X. 2007. Recent developments in sample preparation techniques for chromatography analysis of traditional Chinese medicines-Review. Journal of Chromatography A. 1153(1): 90-96.

[14] Gross, J.H. 2004. Mass spectrometry: A textbook. Germany: Springer-Verlag.

[15] Adams, R.P. 1995. Identification of Essential Oil Components by Gas Chromatography/Mass Spectroscopy. Carol Stream: Allured Publication.

[16] Jennings, W. and Shibamoto, T. 1980. Qualitative Analysis of Flavor and Fragrance Volatiles by Glass Capillary Gas Chromatography. New York: Academic Press.

[17] Verzera, A., Trozzi, A., Cotroneo, A., Lorenzo, D., and Dellacasa E. 2000. Uruguayan Essential Oil. 12. Composition of Nova and Satsuma Mandarin Oils. J. Agric. Food Chem. 48: 2903-2909.

[18] Tajuddin, S.N., and Yusoff, M.M. 2010. Chemical composition of volatile oils of Aquilaria malaccensis (Thymelaeaceae) from Malaysia. Natural Product Communications, 5(12): 1965-1968. 
[19] D. T. T. Thuy, T. T. Tuyen, T. T. T. Thuy, P. T. H. Minh, Q. T. Tran, P. Q. Long, et al. 2019. Isolation process and compound identification of agarwood essential oils from Aquilaria crassna cultivated at three different locations in Vietnam. Processes, $7: 432$.

[20] M. Sahlan, A. M. Fadhan, D. K. Pratami, K. Lischer, A. Wijanarko, H. Hermansyah. 2019. Encapsulation of Agarwood Essential Oil with Maltodextrin and Gum Arabic. Chemical Engineering. 10(8): 1541-1547. 